\title{
Evaluation of Burden and Anxiety in Caregivers of Patients with Pediatric Celiac Disease in the COVID-19 Pandemic
}

\author{
Ibrahim Hakan Bucak ${ }^{1, \oplus}$ Gokhan Tumgor ${ }^{2} \quad$ Habip Almis ${ }^{1, \oplus}$ Sumeyye Kose ${ }^{1}$ \\ Cagla Nur Dogan ${ }^{3, \odot}$ Mehmet Turgut ${ }^{4, \odot}$ \\ ${ }^{1}$ Department of Pediatrics, Adiyaman University School of \\ Address for correspondence Ibrahim Hakan Bucak, MD, \\ Medicine, Adiyaman, Turkey \\ 2 Department of Pediatric Gastroenterology, Cukurova University \\ School of Medicine, Adana, Turkey \\ ${ }^{3}$ Department of Pediatrics, Cukurova University School of Medicine, \\ Altınsehir Neighborhood 3012 Street Manas Site G Bloc Floor \\ 7 No: 32 Adıyaman 02040, Turkey (e-mail: ihbucak@hotmail.com, \\ drhbucak@hotmail.com). \\ Adana, Turkey \\ ${ }^{4}$ Department of Pediatric Infectious Disease, Adiyaman University \\ School of Medicine, Adiyaman, Turkey
}

Avicenna J. Med. 2021;3:152-155.

\begin{abstract}
Background Anxiety and caregiver burden increase among caregivers for individuals with chronic disease. The purpose of this study was to compare the anxiety levels and caregiver burden among caregivers for cases with pediatric celiac disease (CD) before and during the COVID-19 pandemic.

Materials and Methods The Zarit Burden Interview (ZBI) and the Beck Anxiety Inventory (BAI) were applied to 29 parents caring for pediatric CD patients in January 2020, when COVID-19 cases had not yet been seen in Turkey. The study was designed prospectively. The scales were also reapplied to the same study group online during the COVID-19 pandemic (May 2020). The results were then compared.

Results Parents caring for 29 cases of pediatric CD; 21 mothers (72.4\%), six fathers (20.7\%), and two aunts (6.9\%) took part in the study. Mean ZBI scores before and

Keywords

- coronavirus disease 2019

- celiac disease

- anxiety

- burden during the COVID-19 pandemic were $27.51 \pm 14.12$ (8-73) and $38.68 \pm 10.95$ (21-57), respectively $(p<0.01)$. Mean BAI scores before and during the COVID-19 pandemic were $13.27 \pm 7.65(1-27)$ and $23.48 \pm 12.40(2-48)$, respectively $(p<0.01)$.

Conclusion Increased anxiety and caregiver burden among caregivers of pediatric $C D$ cases during the COVID-19 pandemic were identified for the first time in the literature in this study.
\end{abstract}

\section{Introduction}

Celiac disease $(C D)$ is a multisystemic genetic disease characterized by emerging clinical findings, following the consumption of wheat gliadins and associated prolamins in genetically disposed individuals. ${ }^{1}$ The reported prevalence in the general

published online September 6, 2021
DOI https://doi.org/

10.1055/s-0041-1735382

ISSN 2231-0770 population is 0.5 to $1 \%{ }^{2}$ The pathophysiology of $\mathrm{CD}$ involves atrophy resulting from inflammation in the villi of the small intestine. ${ }^{3,4}$ Patients and families have to cope with numerous clinical findings such as chronic diarrhea, growth retardation and developmental delay, vomiting, short stature, anemia, osteopenia, ataxia, and peripheral neuropathy. ${ }^{1,5}$ (c) 2021. Syrian American Medical Society.

This is an open access article published by Thieme under the terms of the Creative Commons Attribution-NonDerivative-NonCommercial-License, permitting copying and reproduction so long as the original work is given appropriate credit. Contents may not be used for commercial purposes, or adapted, remixed, transformed or built upon. (https://creativecommons.org/licenses/by-nc-nd/4.0/).

Thieme Medical and Scientific Publishers Private Limited A-12, Second Floor, Sector -2, Noida-201301, Uttar Pradesh 
The most effective known treatment is currently a lifetime gluten-free diet. ${ }^{1-3}$ The majority of the above clinical findings resolve after such a diet. Lifetime diet therapy and obtaining gluten-free products affect both parents and the emotional state of sick children. Higher levels of depression and anxiety have previously been reported in caregivers of individuals with CD compared with a control group. ${ }^{6}$

Coronavirus disease 2019 (COVID-19) is having a hitherto unmatched impact. Lockdowns imposed in the majority of countries, together with closures of schools, children's playgrounds, shopping malls, restaurants, and mass transportation, and restrictions on activities due to social distancing, are affecting both children and parents. One study from China revealed psychiatric effects (depression, anxiety, and stress) caused by the COVID-19 pandemic in participants, together with anxiety for family members. ${ }^{7}$ The first officially reported case in Turkey was on March 11, 2020, after which individuals under 20 years and over 65 years were immediately placed on lockdown. This clearly resulted in increased anxiety in society as a whole.

No previous studies have evaluated anxiety levels and the caregiver burden among caregivers for pediatric $C D$ cases during the COVID-19 pandemic. The purpose of this study was to compare anxiety levels and burden among caregivers for cases with pediatric $\mathrm{CD}$ before and during the COVID-19 pandemic.

\section{Materials and Methods}

Gluten-free food preparation education was originally planned for the caregivers of cases of pediatric $\mathrm{CD}$ registered with our provincial Celiac Association in January 2020 under the scope of the "Gluten-Free Cuisine for a Healthy Life" project. The aim was to assess the effect of the education to be provided on the caregiver burden and anxiety of caregivers for pediatric $C D$ cases. Twenty-nine patients were included in the study. The Zarit Burden Interview (ZBI) and the Beck Anxiety Inventory (BAI) were applied to parents before the education, between 15 and 20 January, 2020. However, the planning was subsequently cancelled due to the appearance of the COVID-19 pandemic in Turkey. The same inventories were again applied to the same population during the COVID-19 pandemic and the accompanying limitations imposed at that time (21 to 25 May, 2020). Informed consent was obtained from each patient included in the study. Approval for the study was granted by the Turkish Ministry of Health (permission form no. 2020-05-27T09_54_22) and the local ethical committee (no. 2019/8-22). The study protocol conformed to the ethical guidelines of the 1975 Declaration of Helsinki (6th revision, 2008), as reflected in a priori approval by the institution's human research committee.

The BAI is a 21-item self-report questionnaire investigating common symptoms of anxiety, such as nervousness, feeling afraid, and fear of dying, and was designed to distinguish anxiety symptoms from depressive symptoms. Each item is rated on a 4-point Likert scale in terms of symptom severity in the previous week, ranging from 0 (none) to 3 (severe). Total scores range from 0 to 63 , higher scores indicating greater degrees of anxiety. The recommended clinical classifications of the total scale scores are as follows: scores of 0 to 7 suggest minimal anxiety, 8 to 15 mild anxiety, 16 to 25 moderate anxiety, and 26 to 63 severe anxiety. ${ }^{8,9}$ The reliability and validity of the BAI for Turkey have already been established. ${ }^{10}$

The ZBI consists of 22 items on a 5-point Likert scale from 0 (never) to 4 (nearly always), apart from for the final item on global burden, which is rated from 0 (not at all) to 4 (extremely). Total possible scores range from 0 to 88 , higher values indicating greater burden. ${ }^{11,12}$ The reliability and validity of the ZBI for Turkey have already been established. ${ }^{13}$

\section{Statistical Analysis}

SPSS version 13 for Windows (SPSS, Chicago, IL, USA) was used for statistical analysis. Categorical data were expressed as number and percentage, and constant variables as mean plus standard deviation (SD). The Kolmogorov-Smirnov test applied to determine the distribution of variables during data comparison revealed that the variables were normally distributed $(p>0.05)$. Data were therefore compared using the independent samples $t$-test.

\section{Results}

Twenty-nine caregivers of pediatric $\mathrm{CD}$ cases took part in the study, 21 (72.4\%) mothers, six fathers (20.7\%), and two (6.9\%) aunts. The mean age of the caregivers was $39.17 \pm 7.56$ years (27-56). The demographic data obtained in the study are shown in - Table 1.

The mean ZBI score on first completion was $27.51 \pm$ 14.12 (8-73), rising to $38.68 \pm 10.95$ (21-57) during the COVID-19 pandemic. The difference between the two test results was statistically significant $(p<0.01)$. The mean BAI score on first completion was $13.27 \pm 7.65$ (1-27), rising to $23.48 \pm 12.40$ (2-48) during the COVID-19 pandemic. The differences between the two test scores was also significant $(p<0.01)$. A classification of caregivers based on BAI results is shown in - Table 2.

\section{Discussion}

The results of this study showed increases in the caregiver burden based on the ZBI $(p<0.01)$ and in anxiety based on the BAI $(p<0.01)$ among caregivers for cases of pediatric CD during the COVID-19 pandemic. This is the first study to demonstrate an increase in caregiver anxiety and burden among caregivers for $\mathrm{CD}$ cases during the COVID-19 pandemic compared with the pre-COVID-19 period.

Even decades after the event, the COVID-19 pandemic will be remembered for leaving behind its irreversible effects. These may include COVID-19-related depression, anxiety, sleep disorder, and increased suicide rates, the worst economic recession to date, and deep-rooted changes in the health system. ${ }^{14-16}$ The parents of children with chronic disease are more seriously impacted by these effects than society in general. Stojanovic et al. ${ }^{17}$ determined anxiety levels of $34.5 \%$ and $23.3 \%$, respectively, in their study of $116 \mathrm{CD}$ 
Table 1 Participant and CD case data

\begin{tabular}{|c|c|}
\hline $\begin{array}{l}\text { Parents taking part in the } \\
\text { study }\end{array}$ & \\
\hline Age (years) & $39.17 \pm 7.56(27-56)$ \\
\hline Degree of proximity & $n(\%)$ \\
\hline Mother & $21(72.4)$ \\
\hline Father & $6(20.7)$ \\
\hline Other (aunt) & $2(6.9)$ \\
\hline Occupation & $n(\%)$ \\
\hline No regular income & $13(44.8)$ \\
\hline Housewife & $7(24.1)$ \\
\hline Manual & $3(10.3)$ \\
\hline Clerical & $3(10.3)$ \\
\hline Engineer & $1(3.4)$ \\
\hline Teacher & $1(3.4)$ \\
\hline Health worker & $1(3.4)$ \\
\hline \multicolumn{2}{|l|}{ Family income } \\
\hline Below minimum wage & $7(24.1)$ \\
\hline $\begin{array}{l}\text { Minimum wage (341.2 } \\
\text { dollars) }\end{array}$ & $16(55.2)$ \\
\hline Above minimum wage & $6(20.7)$ \\
\hline \multicolumn{2}{|l|}{ Celiac patients } \\
\hline Age (years) & $10.1 \pm 3.72(4-18)$ \\
\hline \multicolumn{2}{|l|}{ Sex } \\
\hline Female & $13(44.8)$ \\
\hline Male & $16(55.2)$ \\
\hline
\end{tabular}

Abbreviation: CD, celiac disease.

Minimum wage 2324 Turkish lira (= $341.2 \$$ ), Turkish Republic Central Bank Exchange Rate on 29.05.2020: 6.81 lira to $1 \$ .31$

cases and parents. Ludvigsson et $\mathrm{al}^{6}$ reported an $8 \%$ higher risk of anxiety and depression in the parents of $C D$ cases compared with a control group. Anxiety level elevation has previously been identified in parental caregivers for individuals with various chronic diseases. Studies involving psoriasis, atopic dermatitis, vitiligo, asthma, chronic kidney diseases, cystic fibrosis, and functional abdominal pain have all revealed parental anxiety. ${ }^{18-22}$ Measures capable of reducing the anxieties of parents caring for patients with CD need to be adopted both during and after the COVID-19 pandemic.

The individual who cares for a patient with chronic disease is responsible for that person's daily activities (toilet, bathing, eating, walking, etc.) and for providing medical support (medications, hospital appointments, etc.). ${ }^{23}$ Parental burdens have been demonstrated in numerous chronic diseases, such as cancers, neurological diseases, and autism spectrum disorder. ${ }^{23-27}$ Parents caring for patients with chronic disease are also known to require social, financial, and psychological support. ${ }^{28}$ The present study confirms that the caregiver burden among caregivers for $\mathrm{CD}$ cases has risen during the COVID-19 pandemic compared with the prepandemic period. Individuals caring for cases with chronic diseases are not routinely assessed in terms of caregiver burden. The data
Table 2 Group distributions by BAl scores

\begin{tabular}{|l|l|l|}
\hline & \multicolumn{2}{|c|}{$n$ (\%) } \\
\hline BAl groups & $\begin{array}{l}\text { First } \\
\text { application } \\
\text { result }\end{array}$ & $\begin{array}{l}\text { Second } \\
\text { application result }\end{array}$ \\
\hline Minimal (score 0-7) & $9(31)$ & $3(10.3)$ \\
\hline Mild (8-15) & $7(24.1)$ & $7(24.1)$ \\
\hline Moderate (16-25) & $11(37.9)$ & $6(20.7)$ \\
\hline Severe (26-63) & $2(6.9)$ & $13(44.8)$ \\
\hline
\end{tabular}

Abbreviation: BAl, Beck Anxiety Inventory.

from the present study show that individuals caring for such cases should also be evaluated in terms of burnout at routine clinical examinations of pediatric CD cases. In a study from Italy, Ferretti et al..$^{29}$ reported that alarm symptoms (abdominal pain, weight loss, and chronic diarrhea) also exhibited an anxiety-exacerbating effect among caregivers of CD cases. Their quality of life is known to improve once $C D$ cases have been diagnosed and started on a gluten-free diet. ${ }^{29,30}$ One review study involving caregivers of individuals with chronic disease emphasized the need for caregivers to be educated about the disease, for health workers to share their treatment plans with the caregiver, and for caregivers to be provided with social and material support and support in terms of coping with the disease. ${ }^{23}$ The present study revealed the need for caregivers of pediatric CD cases to receive more evaluation in terms of burden. This has become more apparent during the COVID-19 pandemic.

The limitations of this study are the fact that an anxiety scale was not applied to the pediatric $C D$ patients included in the study, the low number of participants, and the absence of a control group consisting of parents of healthy children.

\section{Conclusion}

The anxiety and caregiver burden among caregivers for patients with pediatric $C D$ have increased markedly during the COVID-19 pandemic. We conclude that caregivers should also be evaluated in terms of anxiety and caregiver burden during the examination of pediatric CD cases. In addition, we think that support aimed at reducing anxiety should be provided for families with chronic diseases such as CD under conditions that impact on routine life, such as natural disasters and epidemics.

Note

Authors have reviewed the article and approved the final version of article.

\section{Authors' Contribution}

1. Study concept and design: I.H.B., G.T., and M.T.

2. Acquisition of data: I.H.B., H.A., S.K., and C.N.D.

3. Analysis and interpretation of data: I.H.B., G.T., H.A., S.K., and M.T.

4. Drafting of the manuscript: I.H.B., G.T., C.N.D., and H.A.

5. Critical revision of the manuscript for important intellectual content: G.T. and M.T.

6. Statistical analysis: S.K., C.N.D., and H.A. 
7. Administrative, technical, and material support: S.K. and N.D.

8. Study supervision: I.H.B., H.A., and G.T.

\section{Conflict of Interest}

The authors declare that they have no conflict of interest.

\section{References}

1 Troncone R, Auricchio S, Celiac disease. In: Wyllie R, Hyams JS, Kay M, editors. Pediatric Gastrointestinal and Liver Disease. Philadelphia: Elsevier; 2016

2 Caio G, Volta U, Sapone A, et al. Celiac disease: a comprehensive current review. BMC Med 2019;17(1):142

3 Al-Bawardy B, Codipilly DC, Rubio-Tapia A, Bruining DH, Hansel SL, Murray JA. Celiac disease: a clinical review. Abdom Radiol (NY 2017;42(2):351-360

4 Oxentenko AS, Rubio-Tapia A. Celiac disease. Mayo Clin Proc 2019;94(12):2556-2571

5 Zylberberg HM, Lebwohl B, Green PHR. Celiac diseasemusculoskeletal manifestations and mechanisms in children to adults. Curr Osteoporos Rep 2018;16(6):754-762

6 Ludvigsson JF, Roy A, Lebwohl B, Green PHR, Emilsson L. Anxiety and depression in caregivers of individuals with celiac disease - A population-based study. Dig Liver Dis 2017;49(3):273-279

7 Xiao H, Zhang Y, Kong D, Li S, Yang N. The effects of social support on sleep quality of medical staff treating patients with Coronavirus disease 2019 (COVID-19) in January and February 2020 in China. Med Sci Monit 2020;26:e923549

8 Beck AT, Epstein N, Brown G, Steer RA. An inventory for measuring clinical anxiety: psychometric properties. J Consult Clin Psychol 1988;56(6):893-897

9 Carney CE, Moss TG, Harris AL, Edinger JD, Krystal AD. Should we be anxious when assessing anxiety using the Beck Anxiety Inventory in clinical insomnia patients? J Psychiatr Res 2011;45(9):1243-1249

10 Ulusoy M, Sahin N, Erkmen H. Turkish version of the Beck Anxiety Inventory: Psychometric Properties. J Cogn Psychother 1998;12:163-172

11 Zarit SH, Reever KE, Bach-Peterson J. Relatives of the impaired elderly: correlates of feelings of burden. Gerontologist 1980;20(6):649-655

12 Gonçalves-Pereira M, González-FraileE,Santos-Zorrozúa B, etal. Assessment of the consequences of caregiving in psychosis: a psychometric comparison of the Zarit Burden Interview (ZBI) and the Involvement Evaluation Questionnaire (IEQ. Health Qual Life Outcomes 2017;15(1):63

13 Available at: https://toad.halileksi.net/sites/default/files/pdf/ bakim-verme-yuku-olcegi-toad.pdf. Accessed September 2, 2020

14 Sher L. COVID-19, anxiety, sleep disturbances and suicide. Sleep Med 2020;70:124

15 Danielli S, Patria R, Donnelly P, Ashrafian H, Darzi A. Economic interventions to ameliorate the impact of COVID-19 on the economy and health: an international comparison. J Public Health (Oxf 2021;43(1):42-46

16 Remuzzi A, Remuzzi G. COVID-19 and Italy: what next.? Lancet 2020;395(10231):1225-1228

17 Stojanović B, Kočović A, Radlović N, et al. Assessment of quality of life, anxiety and depressive symptoms in Serbian children with celiac disease and their parents. Indian J Pediatr 2019;86(5):427-432

18 Manzoni AP, Weber MB, Nagatomi AR, Pereira RL, Townsend RZ, Cestari TF. Assessing depression and anxiety in the caregivers of pediatric patients with chronic skin disorders. An Bras Dermatol 2013;88(6):894-899

19 Szabó A, Mezei G, Kovári E, Cserháti E. Depressive symptoms amongst asthmatic children's caregivers. Pediatr Allergy Immunol 2010;21(4 Pt 2):e667-e673

20 Lima AGT, Sales CC, Serafim WFL. Burden, depression and anxiety in primary caregivers of children and adolescents in renal replacement therapy. J Bras Nefrol 2019;41(3):356-363

21 Quittner AL, Goldbeck L, Abbott J, et al. Prevalence of depression and anxiety in patients with cystic fibrosis and parent caregivers: results of The International Depression Epidemiological Study across nine countries. Thorax 2014;69(12):1090-1097

22 Cunningham NR, Cohen MB, Farrell MK, Mezoff AG, Lynch-Jordan A, Kashikar-Zuck S. Concordant parent-child reports of anxiety predict impairment in youth with functional abdominal pain. J Pediatr Gastroenterol Nutr 2015;60(3):312-317

23 Adelman RD, Tmanova LL, Delgado D, Dion S, Lachs MS. Caregiver burden: a clinical review. JAMA 2014;311(10):1052-1060

24 Statham C, Davis C. Psychological burden of haematological cancer on patient and family: is it time for a multisystem approach. ? Curr Opin Support Palliat Care 2018;12(4):518-521

25 Olagunju AT, Sarimiye FO, Olagunju TO, Habeebu MY, Aina OF. Child's symptom burden and depressive symptoms among caregivers of children with cancers: an argument for early integration of pediatric palliative care. Ann Palliat Med 2016;5(3):157-165

26 Lue YJ, Chen SS, Lu YM. Factors affecting the health-related quality of life of caregivers of patients with muscular dystrophy. J Neurol 2018;265(7):1548-1556

27 Picardi A, Gigantesco A, Tarolla E, et al. Parental burden and its correlates in families of children with autism spectrum disorder: a multicentre study with two comparison groups. Clin Pract Epidemiol Ment Health 2018;14:143-176

28 Toledano-Toledano F, Domínguez-Guedea MT. Psychosocial factors related with caregiver burden among families of children with chronic conditions. Biopsychosoc Med 2019;13:6

29 Ferretti F, Branchi F, Dell'Osso B, Conte D, Elli L. Coping with celiac disease: how heavy is the burden for caregivers? Rev Esp Enferm Dig 2017;109(4):250-255

30 Nachman F, Mauriño E, Vázquez H, et al. Quality of life in celiac disease patients: prospective analysis on the importance of clinical severity at diagnosis and the impact of treatment. Dig Liver Dis 2009;41(1):15-25

31 Available at: https://www.tcmb.gov.tr/kurlar/kurlar_tr.html. Accessed June 1, 2020 